\title{
BP NEURAL NETWORK-BASED SMOG ENVIRONMENT AND THE RISK MODEL OF MOOD DRIVING
}

\author{
You, Z. ${ }^{1,3}-$ LIU, J. $^{2}-$ DAI, J. ${ }^{2}-$ LIU, W. ${ }^{3}-$ SONG, W. ${ }^{4}-$ WANG, X. ${ }^{1}-$ ZHANG, C. ${ }^{5}$ \\ ${ }^{1}$ School of Digital Media and Design Arts, Beijing University of Posts and Telecommunications \\ Beijing 100876, China \\ ${ }^{2}$ College of Architecture and Urban Planning, Beijing University of Technology \\ Beijing 100124, China \\ ${ }^{3}$ User Experience Research Center, Faculty of Psychology, Beijing Normal University \\ Beijing 100875, China \\ ${ }^{4}$ College of Mechanical Engineering and Automation, Huaqiao University \\ Xiamen 362021, China \\ ${ }^{5}$ School of Electrical and Information Engineering, Wuhan Institute of Technology \\ Wuhan 430074, China \\ *Corresponding author \\ e-mail: ljym66@163.com
}

(Received 24 $4^{\text {th }}$ Mar 2017; accepted $19^{\text {th }}$ May 2017)

\begin{abstract}
In order to evaluate and study the influence of smog environment on driving safety, this paper utilizes the measurability of mood states, adopts back propagation (BP) artificial neural network instrument to establish a smog-risky mood network model. Six pictures in different smog levels were used as emotional stimuli to verify the BPM neural network-based smog-risky mood relation model. The result shows that the smog is a main factor affecting the driver's mood. The method of estimating moods based on the smog environment of BP network is able to predict $70 \%$ of the danger. It was proved to be an effective means for the safety management and self-detection of drivers, especially professional drivers.
\end{abstract}

Keywords: environmental engineering, driving safety, smog, human factor, profile of mood state

\section{Introdaction}

Since severe smog appeared in Beijing and many cities in Central and East China in Jan. 2013 as a hot topic for all sectors of society, the smog situation has drawn wide attention from both home and abroad (Sun et al., 2013; Guo, 2014; Zhang et al., 2014; Raza et al., 2015). According to Watts' formulation (Gleick, 2003), smog is a multicomponent air pollutant, which is usually visible to naked eyes and sometimes even exists in forms of tactile molecules. Smog mainly comes from, but not limited to industrial production and the combustion of fossil fuels. Considering the severe damage of smog towards urban environment and the health of citizens, since Jan. 2014, the National Disaster Reduction Center started to notify the public of smog as a natural disaster. Subsequently, various cities in China began to monitor their smog concentration and provide warnings and forecasts of smog towards the public. The suspended solids with an aerodynamic diameter within 10 micrometers and 2.5 micrometers are named $\mathrm{PM}_{10}$ and $\mathrm{PM}_{2.5}$ (Zhang et al., 2012b). The frequent happening of smog as a weather condition has to do with $\mathrm{PM}_{2.5}$ in air exceeding standard level. The current laws 
and regulations in China concerning the prevention and control of smog are still facing a number of problems including a lagged-behind legislative conception, the lack of governmental responsibilities, the blank of $\mathrm{PM}_{2.5}$ laws and regulations, room for improvement of total quantity control and the supervision of motor vehicle exhaust, etc. (Gao, 2012; Fang et al., 2013; Wagner et al., 2012).

Second, along with the improvement of the economic and material level in China, automobiles have become prevalent in the country, more and more automobiles are used for household outing and industrial transportation, which makes driving safety a key problem for people's attention. Smog frequently occurs, especially in big cities with a large density of automobiles. Statistics have shown that the probability of traffic accidents is much higher under smog weather conditions, being dozens of times higher than under normal weather conditions, thus creating a huge influence upon driving safety (Tai, 2011). Through establishing BP Neural Network Model and training of part of the statistics and information in the model, under the condition of unknown intrasystem patterns, this paper proposes suggestions on safe driving through gaining predictive conclusions on the system by utilizing various evaluative indexes, so as to provide further guarantee for driving safety under smog weather conditions.

\section{Materials and Methods}

Mood state refers to the emotions people manifest under the influence of a certain event or scenario within a set period of time. Before or during driving, drivers are susceptible to experiencing mood changes due to changed subjective and objective factors, which exerts significant influences upon driving safety (Rhodes and Pivik, 2011; Pecher et al., 2009; Slovic et al., 2004; Yeung and Wong, 2015). Positive emotions are conducive to safe driving whereas negative moods might inhibit safe driving by influencing drivers' attention and reaction (White, 2011). Under the influence of negative moods, drivers are susceptible to driving fatigue and might weaken safety awareness. Therefore, studying the emotions of drivers holds huge significance for road traffic safety (Mackenzie and Harris, 2015). The current studies on the emotional states of drivers are mainly devoted to measuring the emotional states of drivers as well as the influence of varying professional characteristics on driving behavior (Chapman and Underwood, 1998; Rhodes and Pivik, 2011; Joanne et al., 2013; Zhang et al., 2012a). This paper adopts Profile of Mood State (POMS) and draws samples upon the emotional states of the drivers in Beijing. Along with smog conditions, it wishes to establish a network topology model on smog influence and the danger of mood driving in order to achieve an in-depth study of the influence of smog on driving mood states and provide a countermeasure based on ergonomics to adjust to smog environment.

\section{Object}

With random selected drivers of long-distance buses, taxis, logistics cars and private cars as test samples, 500 questionnaires have been given out and 437 valid questionnaires $(87.4 \%)$ have been retrieved. The age group of sample drivers is from 21 to 55 years old, including 198 female drivers, 239 male drivers; 108 professional drivers and 329 nonprofessional drivers. 


\section{Methodology}

By adopting Profile of Mood State (POMS), this scale covers 6 questions in mental tension, 6 in fatigue, 7 in anger, 6 in hurriedness, and 7 in depression; in the positive mood part, there are 5 questions on energy and 6 questions on personal information. There are 43 questions in total in the questionnaire and an assignment of 7 values based on the various degrees of the participants' agreement with the statements in the questions. The total score of emotional disorder is $\mathrm{md}=\sum$ scores of negative emotions- $\sum$ scores of positive emotions +100 . In the equation, TMD is the total score of emotional coding. And higher scores imply worse mood states and a more dangerous driving process.

\section{Statistics of the Current Situation}

The research uses SPSS to analyze the statistics in the sample. Through a descriptive analysis, TMD normal distribution P- figure $\mathrm{P}$ is obtained. As shown in Fig. 1, the expected normal distribution falls approximately on a line, i.e. the TMD of the sample obeys normal distribution. The average level of TMD is 104.89 , and the variance is 434.933 , with a distributing scope of 60-181.

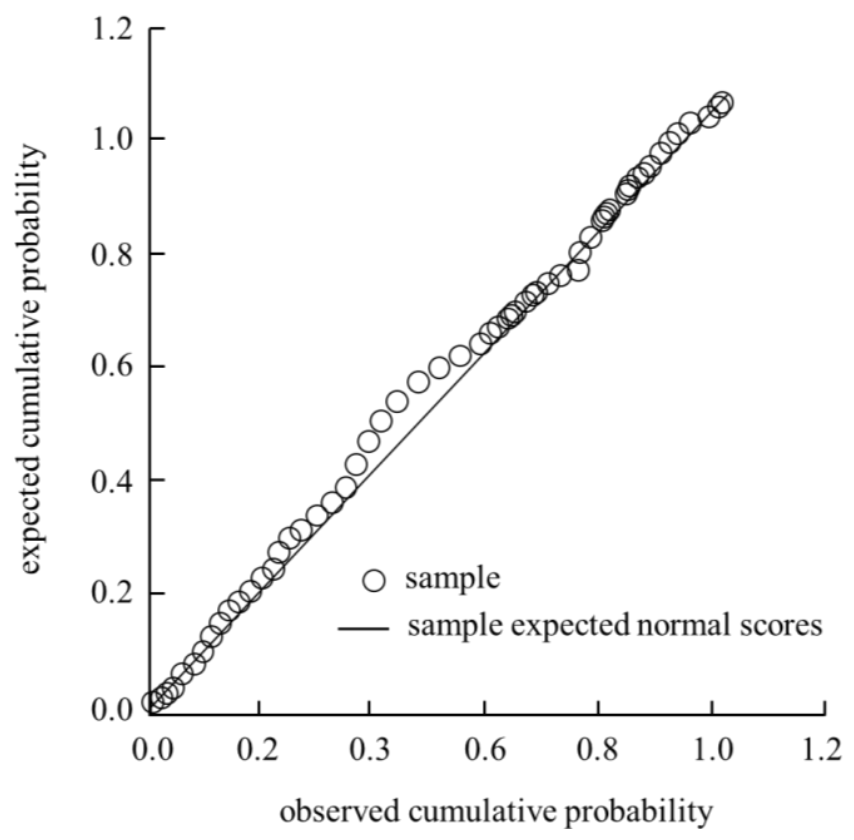

Figure 1. De Normal P - P curves of TMD

Through further analysis, the following conclusion can be made: among 437 drivers, the TMD of 30 participants equals to or is higher than 136, i.e. their moods are in a negative state. Statistics on the profession and gender of the drivers are shown in Table 1.

From Table 1, it can be drawn that the probability of professional drivers having negative emotions is much higher than non-professional drivers, which is pertinent to the fact that professional drivers often work in a highly intensive manner and for a long time. The probability of male drivers having negative emotions is much higher than female drivers. The sample is distributed into five age groups and the number of people with negative emotions is seen in Table 2. 
Table 1. Relationship between drivers 'characteristics and negative mood

\begin{tabular}{cccccc}
\hline & $\begin{array}{c}\text { The number of } \\
\text { participants with } \\
\text { pro negative } \\
\text { influence/ the total }\end{array}$ & Probability & Gender & $\begin{array}{c}\text { The number of } \\
\text { participants with } \\
\text { pro negative } \\
\text { influence/ the total }\end{array}$ & Probability \\
\hline Occupational & $6 / 108$ & 5.6 & female & $3 / 198$ & 1.51 \\
\hline $\begin{array}{c}\text { Non- } \\
\text { occupational }\end{array}$ & $9 / 329$ & 2.7 & male & $11 / 239$ & 4.6 \\
\hline
\end{tabular}

Table 2. Drivers' negative emotion scale of each age interval

\begin{tabular}{cccc}
\hline $\begin{array}{c}\text { Age } \\
\text { range }\end{array}$ & $\begin{array}{c}\text { The number of } \\
\text { participants }\end{array}$ & $\begin{array}{c}\text { The number/ratio of participants with pro } \\
\text { negative influence }\end{array}$ & Probability \\
\hline $21-30$ & 135 & 9 & 6.7 \\
\hline $31-40$ & 161 & 12 & 7.4 \\
\hline $41-50$ & 98 & 7 & 7.1 \\
\hline $51-60$ & 32 & 1 & 3.1 \\
\hline $61-65$ & 11 & 0 & 0 \\
\hline
\end{tabular}

Table 2 shows that the age group who are most likely to experience negative emotions is 21 to 30 , with 31 to 40 running in the next place. With the increase of age, the awareness of safe driving, driving skills, the maturity of mental state and stability, the probability of negative emotions gradually decreases.

\section{Smog's Infuence on Driving Mood}

The environmental pollution brought about by rapid economic development has led to the deterioration of human beings' living environment. The physical health of human beings is influenced by environmental deterioration, which has induced public anxiety and panic. In recent years, interdisciplinary studies, especially environmental science and design and the combination of intelligence algorithm have exhibited a huge advantage in exploring the management of environmental crisis (Zhao et al., 2013; Duan et al., 2012; Maenhaut et al., 2011; Wu et al., 2012; Zhi et al., 2014). Although the perception of the drivers is a matter of cognitive psychology, the perception of the damage of smog should not break away from scientific cognition of the essence of smog and its physical characteristics. However, with the continuous development and change of pollution, concrete evaluative methods have experienced a series of changes. For example, air quality index has replaced the index of pollution, which makes the scientific evaluation of air pollution more suitable for the perception of residents; apart from the total concentration of pollutants, there is an increase of elaborate sub-indexes, respectively representing the concentration of various suspended solids; apart from $\mathrm{O}_{3}, \mathrm{SO}_{2}, \mathrm{CO}, \mathrm{NO}_{2}$. $\mathrm{PM}_{2.5}$ has an important influence on reducing the atmospheric visibility (Zhang et al., 2012b), and also monitors the breaking point statistics and average pollutant concentration. This is particularly true for $\mathrm{PM}_{2.5}$, since it can penetrate human lungs and induce serious illnesses, thus becoming a top priority for scientific research and environmental management. Currently, the relatively advanced air quality evaluation technology is Air Quality Index (AQI), which represents the degree of air pollution, with an evaluation scope of 0 to 500. At the same time, this evaluative system, 
based on the AQI value, divides air quality into six degrees from good to severely polluted. Although AQI monitoring technology was born in as early as 1999 (Xue et al., 2015), the expensiveness of the monitoring device has made it only circulated in a small number of countries including the United States and China. In the beginning of 2012, the new Ambient Air Quality Standard (GB3095-2012) (Streets et al., 2007) was issued in China, and the corresponding air quality evaluation system was officially changed to AQI (Wang et al., 2010). Nowadays, most metropolises, Beijing included, are continuously announcing AQI instant messages to the public (Chan and Yao, 2008; Fu et al., 2012; Cheng et al., 2015).

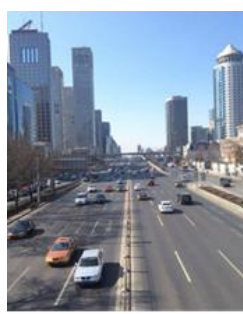

Good

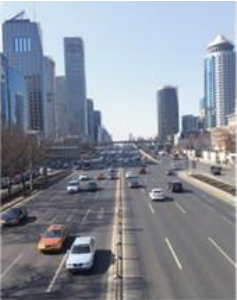

Moderate

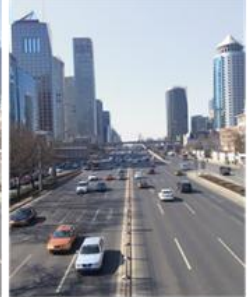

Lightly Polluted Moderately Polluted

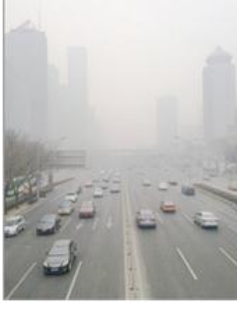

Heavily Polluted

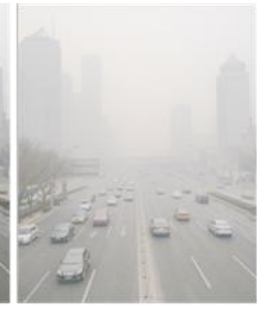

Severely Polluted

Figure 2. Emotional pictures (actual photos)

Based on the analysis, this paper sets (AQI6) levels of air quality as the influential factors of drivers and conducts a questionnaire survey on the mood of drivers. The survey adopts emotional pictures (Fig. 2) to induce positive and negative emotions and compares individual emotions. The survey results are seen in Table 3.

From Table 3, it can be seen that for most drivers, smog has an influence over their moods, with only an extremely small number of drivers as the exception. Based on the investigation and statistics of the mood of drivers, and the smog environment, a smog environment-driver emotional relationship model is established.

Table 3. Statistics of effect of smog environment on drivers' mood

\begin{tabular}{cccccc}
\hline $\begin{array}{c}\text { Influence } \\
\text { factor }\end{array}$ & $\begin{array}{c}\text { The } \\
\text { number/ratio } \\
\text { of } \\
\text { participants } \\
\text { with negative } \\
\text { influence }\end{array}$ & $\begin{array}{c}\text { The } \\
\text { number/ratio } \\
\text { of } \\
\text { participants } \\
\text { with pro- } \\
\text { negative } \\
\text { influence }\end{array}$ & $\begin{array}{c}\text { The } \\
\text { number/ratio } \\
\text { without } \\
\text { influence }\end{array}$ & $\begin{array}{c}\text { The } \\
\text { number/ratio } \\
\text { of participants } \\
\text { with pro- } \\
\text { positive } \\
\text { influence }\end{array}$ & $\begin{array}{c}\text { The } \\
\text { of participants } \\
\text { with positive } \\
\text { influence }\end{array}$ \\
\hline Good & $0 / 0 \%$ & $0 / 0 \%$ & $9 / 2.05 \%$ & $29 / 6.63 \%$ & $399 / 91.3 \%$ \\
\hline Moderate & $0 / 0 \%$ & $2 / 0.46 \%$ & $38 / 8.7 \%$ & $126 / 28.8 \%$ & $271 / / 62.01 \%$ \\
\hline $\begin{array}{c}\text { Lightly } \\
\text { Polluted }\end{array}$ & $23 / 5.26 \%$ & $160 / 36.61 \%$ & $157 / 35.9 \%$ & $39 / 8.92 \%$ & $48 / 10.9 \%$ \\
\hline $\begin{array}{c}\text { Moderately } \\
\text { Polluted }\end{array}$ & $322 / 73.9 \%$ & $78 / 17.8 \%$ & $25 / 5.72 \%$ & $7 / 1.6 \%$ & $1 / 0.02 \%$ \\
\hline $\begin{array}{c}\text { Heavily } \\
\text { Polluted }\end{array}$ & $401 / 91.7 \%$ & $22 / 5.03 \%$ & $14 / 3.2 \%$ & $0 / 0 \%$ & $0 / 0 \%$ \\
\hline $\begin{array}{c}\text { Severely } \\
\text { Polluted }\end{array}$ & $399 / 91.3 \%$ & $31 / 7.1 \%$ & $6 / 1.37 \%$ & $0 / 0 \%$ & $0 / 0 \%$ \\
\hline
\end{tabular}




\section{The Smog-Driver Mood Relationship Model Based on BP Neural Network}

From Table 3, it can be seen that for most drivers, smog has an influence over their moods, with only an extremely small number of drivers as the exception. Based on the investigation and statistics of the mood of drivers, and the smog environment, a smog environment-driver emotional relationship model is established.

\section{Research Methodology}

The aim of this research is to establish a relation model between the smog environment and the mood of drivers. It is a multi-input and multi-output structure, and therefore chooses artificial neural network, abbreviated to ANN as the modeling tool. BP algorithm (Hou et al., 2014), as a relatively typical learning method, has a main structure made of an input layer, one or multiple hidden layers and an output layer. The various layers are comprised of multiple neurons (nodes). The output of each mode is determined by the output, input, action function and threshold value.

\section{Establishing A Model}

The model concludes the smog environment into 6 elements, seen in Table 4. X1, $\mathrm{X} 2 \ldots \mathrm{X} 6$ are input neurons.

Table 4. Statistics of effect of smog environment on drivers' mood

\begin{tabular}{cccccc}
\hline $\begin{array}{c}\text { Influence } \\
\text { factor }\end{array}$ & Neurons & Impact value & Influence factor & Neurons & Impact value \\
\hline Good & $\mathrm{X} 1$ & & Moderately Polluted & $\mathrm{X} 4$ & \\
\hline Moderate & $\mathrm{X} 2$ & $1-5$ & Heavily Polluted & $\mathrm{X} 5$ & $1-5$ \\
\hline Lightly Polluted & $\mathrm{X} 3$ & & Severely Polluted & $\mathrm{X} 6$ & \\
\hline
\end{tabular}

The total TMD is a continuous variable between 56 and 216, and with a mid-value of 136, which makes the matching quite difficult. Therefore, TMD is divided into layers and demonstrated in nominal variables. The tested participants with a TMD average value of over 104.89 has exceeded the average level of the total tested participants; the tested participants with a TMD value of over 136 demonstrates a negative emotional influence, which proves to be dangerous for driving. Based on this, TMD is divided into 3 levels, as shown in Table 5.

Table 5. Setting of output variables

\begin{tabular}{|c|c|c|c|}
\hline & $\begin{array}{l}\text { Nominal } \\
\text { Variables }\end{array}$ & $T M D$ & Signification \\
\hline & 1 & $\begin{array}{l}T M D \in \\
{[54,102]}\end{array}$ & $\begin{array}{l}\text { Below the TMD average value exerts little influence on driving } \\
\text { mood }\end{array}$ \\
\hline \multirow[t]{2}{*}{$\mathrm{Y}$} & 2 & $\begin{array}{c}\text { TMD } \in \\
{[103} \\
134]\end{array}$ & $\begin{array}{c}\text { Below the TMD average value and with pro-positive influence } \\
\text { exerts little influence on driving mood. }\end{array}$ \\
\hline & 3 & $\begin{array}{l}T M D \in \\
{[135} \\
214]\end{array}$ & $\begin{array}{l}\text { Exceeds the TMD average value and with negative influence } \\
\text { exerts great influence on driving mood, which proves to be } \\
\text { dangerous. }\end{array}$ \\
\hline
\end{tabular}

Set the nominal variable as the output neuron for MLP neuron network. 


\section{The BP Network Topology Model}

Establish a BP neuron net with 6 input neurons, m hidden neurons and a BP neural network comprised of one output neuron, and the topology chart is shown in Figure 3.

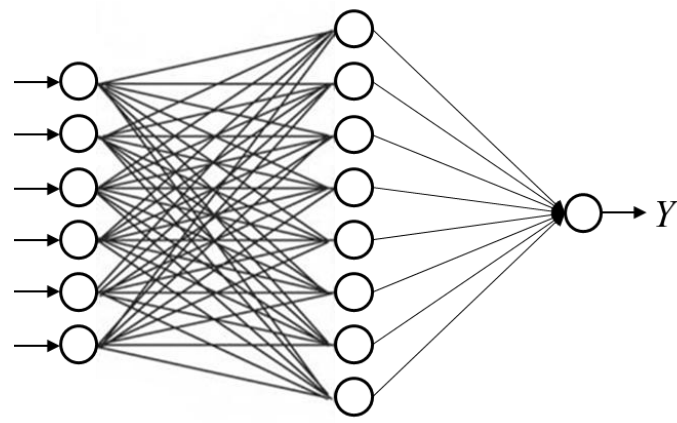

Figure 3. Title of the given figure, graph or image included in the document

As shown in Figure 3, the output of the $\mathrm{j}^{\text {th }}$ neuron is:

$$
u_{j}=\varphi\left(\sum_{i=1}^{8} w_{i j} x_{i}\right), i=1,2, \ldots, 6 ; j=1,2, \ldots, m,
$$

In the equation, $\varphi$ is the activation function; $w_{i j}$ is the connection weight index of the $i^{\text {th }}$ input and the $j^{\text {th }}$ hidden neuron; $\mathrm{xi}$ is the $i^{\text {th }}$ input. Here the hyperbolic tangent function is activated.

$$
\phi_{j}\left[v_{j}(n)\right]=\operatorname{atanh}\left[b v_{j}(n)\right]=\frac{e^{v j(n)}-e^{-v j(n)}}{e^{v j(n)}+e^{-v j(n)}}
$$

Where $\mathrm{a}, \mathrm{b}>0$. In the equation, $v_{j(n)}$ is the induction local field of the $j^{\text {th }}$ hidden neuron; $\mathrm{a}$, $\mathrm{b}$ are the constants; $n$ is an iteration. The output variable is the result of the processing and training of the hidden neurons, presented in equation (3):

$$
y=G\left(u_{o}+\sum_{i=i}^{m} p_{j} u_{j}\right), j=1,2, \ldots, m,
$$

In the equation, $G$ is the activation function of the output; $p_{j}$ is the connection weight index between the $j^{\text {th }}$ hidden neuron and the output neuron; $u_{0}$ is a neuron with a declination. Since the selected output neuron variable is classified, the activation function is a Softmax function:

$$
G_{(c)}=\frac{\exp (c)}{\sum_{j} \exp \left(c_{j}\right)}
$$

In the equation, $c$ is the input variable. Therefore, bring equation (2) to equation (4) and the output variable, i.e. the smog-mood relation calculation model:

$$
y=G\left[u_{0}+\sum_{i=1}^{m} p_{j} \varphi\left(\sum_{i=1}^{8} w_{i j} x_{j}\right)\right]=f(x, \Theta),
$$

In the equation, $x$ is the input variable, i.e. the smog-environment relation and other five self-testing scores; $\Theta$ is the total connection weight index between layers of neurons. 


\section{Results}

127 out of 437 samples were randomly chosen to test whether the BPM neural network-based smog-risky mood relation model can effectively predict the danger. By utilizing SPSS software, an 8:2 setting of training sample capacity and test sample capacity is established for tested samples and the conduction for a prediction for the relationship between the smog environment and moods, and the collected information generated by neuron network model is presented in Table 6 .

Table 6. Summary of neural network model

\begin{tabular}{ccc}
\hline Training & Cross-Entropy Error & $\mathbf{3 6 7 . 6 8 1}$ \\
\hline & Error prediction & $30.8 \%$ \\
\hline Test & Training Time & $0: 00: 00.898$ \\
\hline & Cross-Entropy Error & 90.601 \\
\hline & Error prediction & $28.7 \%$ \\
\hline
\end{tabular}

From Table 6, it can be drawn that $69.2 \%$ of the output neurons obtained through inputting 6 neurons in the training process are correct and the forecast accuracy in the testing process reaches $71.3 \%$. In order to test the stability of the established neuron network, the samples are sorted in a random order and $70 \%, 80 \%$ and $90 \%$ of samples are respectively extracted and based on the same method, a neuron network is established and trained. The training accuracy and prediction accuracy obtained are shown in Table 7.

Table 7. Relationship between accuracy rate and sample size (unit: \%)

\begin{tabular}{lcccc}
\hline & $\begin{array}{c}\mathbf{7 0 \%} \text { sample } \\
\text { size }\end{array}$ & $\begin{array}{c}\mathbf{8 0 \%} \text { sample } \\
\text { size }\end{array}$ & $\begin{array}{c}\mathbf{9 0 \%} \text { sample } \\
\text { size }\end{array}$ & $\begin{array}{c}\mathbf{1 0 0 \%} \text { sample } \\
\text { size }\end{array}$ \\
\hline training accuracy & 68.1 & 69.8 & 70.3 & 69.2 \\
\hline prediction accuracy & 66.7 & 72.1 & 72.9 & 71.3 \\
\hline
\end{tabular}

From Table 7, it shows that there is a 70\% likelihood for the established neuron network model to estimate the risks of the smog-mood relation and dangerous emotions. And the predicted accuracy increases with the enlargement of sample capacity.

Through a systematic calculation, the significance weight of the 6 input neurons' influence over the output neurons is shown in Table 8. From Table 8, it can be seen that the hugest influence on emotions is Severely Polluted and the second place is Heavily Polluted and the next one is Moderately Polluted. What successively come next are Lightly Polluted, Moderate, and Good.

Table 8. Importance of input neurons

\begin{tabular}{lcc}
\hline \multicolumn{1}{c}{ Influence factor } & Importance & normalization \\
\hline Severely Polluted & 0.182 & 87.6 \\
\hline Heavily Polluted & 0.168 & 85.1 \\
\hline Moderately Polluted & 0.101 & 49.7 \\
\hline Lightly Polluted & 0.197 & 33.4 \\
\hline Moderate & 0.150 & 76.1 \\
\hline Good & 0.073 & 37.2 \\
\hline
\end{tabular}




\section{Discussion}

Using Profile of Mood State (POMS), this study investigates the relationship between the smog and the moods of drivers in Beijing. The results conclude that the low visibility caused by the smog reduces the driver's visual sensitivity and increases the driver psychological negative emotions. Concretely, the probability of negative emotions of the professional drivers are much higher than the non-professional drivers. In terms of gender factors, the probability of negative emotion of male drivers is much higher than that of female drivers. In terms of age, with the increase of age, the awareness of safe driving increases, the probability of negative emotion gradually decreased.

Then, using the artificial neural network technology, the method of estimating moods based on the smog environment of BP network is able to predict $70 \%$ of the danger. It was proved to be an effective means for the safety management and self-detection of drivers, especially professional drivers.

Therefore, because the environmental pollution caused by frequent smog, as well as the current unmanned system algorithm is not perfect yet, the drivers need to regulate their moods themselves to achieve safe driving. In smog conditions, they should reduce speed and keep the enough distance from the car in front.

This study is the start of investigating the relationship between driving moods and the smog. Actually, the moods could be influenced by many factors. For example, the moods might be affected by driving alone or with others, especially for the nonprofessional drivers. Moreover, the moods may be affected by the distance and driving time. In further study, the effects of these factors should be verified.

\section{Conclusion}

In order to more accurately estimate the influence of different degrees of smog environment on driving moods, this research, through establishing BP neuron network model and training part of the statistics, is able to obtain predictive conclusions of various estimating criteria under the condition of unknown intra-system patterns, and a systematic conclusion on the system. This paper, through choosing 6 air quality influential factors, establishes a smog-emotion risk model based on BP neuron network and conducts initial application verification. The research shows that smog is the major element influencing the mood of drivers and based on the smog environment of BP network, the methods of estimating moods are able to predict $70 \%$ of the danger, proving to be an effective auxiliary risk estimation method.

\section{REFERENCES}

[1] Chan, C. K., Yao, X. (2008): Air pollution in mega cities in China. - Atmospheric Environment 42(1): 1-42.

[2] Chapman, P. R., Underwood, G. (1998): Visual search of driving situations: Danger and experience. - Perception 27(8): 951-964.

[3] Cheng, M., Zhang, G.. X., Mitran, J. (2015): Global contrast based salient region detection. - IEEE Transactions on Pattern Analysis and Machine Intelligence 37(3): 569-582.

[4] Duan, J. C., Tan, J. H., Wang, S. L. (2012): Roadside, Urban, and Rural comparison of size distribution characteristics of PAHs and carbonaceous components of Beijing, China. - Journal of Atmospheric Chemistry 69(4): 337-349. 
[5] Fang, Z. G., Sun, P., Ouyang, Z. (2013): Studies on the size distribution of airborne microbes at home in Beijing. - Environmental Science 34(7):2526-2532.

[6] Fu, X., Feng, X., Sommar, J. (2012): A review of studies on atmospheric mercury in China. - Science of Total Environment 421/422: 73-81.

[7] Gao, S. (2012): Sources apportionment of $\mathrm{PM}_{10}$ and $\mathrm{PM}_{2.5}$ in five cities in China. Tianjin Medical University, pp. 4-6.

[8] Gleick, P. H. (2003): Global freshwater resources: soft-path solutions for the 21st century. - Science 302(28): 524-1528.

[9] Guo, X. (2014): Digestion method and pollution characteristics of heavy metals of the $\mathrm{PM}_{2.5}$ in typical northeast Beijing. - Master Thesis, Jiangxi Agricultural University, pp. 13-20.

[10] Hou, B., Laped, R. A., Xiao, J. (2014): Learning deep features for scene recognition using places database. - Proceedings of Advances in Neural Information Processing Systems. - MIT Press, Cambridge, Massachusetts, pp. 487-495.

[11] Joanne, M., Wood, M. S., Horswill, P. F. (2013): Evaluation of screening tests for predicting older driver performance and safety assessed by an on-road test. Accident Analysis and Prevention 50(1): 1161-1168.

[12] Mackenzie, A. K., Harris, J. M. (2015): Eye movements and hazard perception in active and passive driving. - Visual Cognition 23(6): 736-757.

[13] Maenhaut, W., Claeys, M., Vercauteren, J. (2011): Comparison of reflectance and transmission in EC/OC measurements of filter samples from Flanders, Belgium. - In: Abstract Book of the 10th International Conference on Carbonaceous Particles in the Atmosphere (ICCPA). Vienna: ICCPA, 26-29.

[14] Pecher, C, L., Cellier, J. M. (2009): Emotions drive attention: Effects on driver's behavior. - Safety Science 47(9): 1254-1259.

[15] Raza, F., Amin, A., Faisal, M. (2015): Desiccation-Tolerant Rhizobacteria from Cholistan Desert, Pakistan, and Their Impact on Zea mays L. - Polish Journal of Environmental Studies 24: 1773-1781.

[16] Rhodes, N., Pivik, K. (2011): Age and gender differences in risky driving: The roles of positive affect and risk perception. - Accident Analysis \& Prevention 43(3): 923931.

[17] Slovic, P., Finucane, M. L., Peters, E. (2004): Risk as analysis and risk as feelings: Some thoughts about affect reason risk and rationality. - Risk analysis 24(2): 311322.

[18] Streets, D. G., Fu, J. S., Jang, C. J. (2007): Air quality during the 2008 Beijing Olympic Games. - Atmospheric Environment 41(3): 480-492.

[19] Sun, Y. Ma, Z. Niu, T. (2013): Characteristics of climate change with respect to fog days and haze days in China in the past 40 years. - Climatic and Environmental Research 18(3): 397-406.

[20] Tai, D. (2011): Traffic control method and countermeasure research of highway on foggy day. - Master Thesis, School of Transportation and logistics, Southwest Jiao tong University, Chengdu.

[21] Wang, X., Liang, X., Jiang, W. (2010): WRF-Chem simulation of East Asian air quality: sensitivity to temporal and vertical emissions distributions. - Atmospheric Environment 44(5): 660-669.

[22] Wagner, R., Ajtai, T., Kandler, K. (2012): Complex refractive indices of Saharan dust samples at visible and near UV wavelengths: a laboratory study. - Atmospheric Chemistry and Physics 12(5): 2491-2512.

[23] White, M. J., Cunningham, L. C., Titchener, K. (2011): Young drivers' optimism bias for accident risk and driving skill: Accountability and insight experience manipulations. - Accident Analysis and Prevention 43(4): 1309-1315.

[24] Wu, C., Huang, J. (2012): Determination of elemental and organic carbon in PM2. 5 in the Pearl River Delta region: inter-instrument (Sunset vs DRI Model 2001 Thermal /Optical Carbon Analyzer) and inter-protocol comparisons (IMPROVE vs. ACE-Asia Protocol). - Aerosol Science and Technology 46(6): 610-621. 
[25] Xue, X. T., Zhang, Q., He, H. (2015): A budget analysis of the formation of haze in Beijing. - Atmospheric Environment 100: 25-36.

[26] Yeung, J. S., Wong, Y. D. (2015): Effects of driver age and experience in abrupt onset hazards. - Accident Analysis and Prevention 26(78): 110-117.

[27] Zhang, W., Capps, S. L., Hu, Y. (2012a): Development of the high order decoupled direct method in three dimensions for particulate matter: enabling advanced sensitivity analysis in air quality models. - Geoscientific Model Development 5(2): 355-368.

[28] Zhang, X., Wang, Y., Niu, T. (2012b): Atmospheric aerosol compositions in China: Spatial/temporal variability, chemical signature, regional haze distribution and comparisons with global aerosols. - Atmospheric Chemistry Physics 11: 2657126615.

[29] Zhang, Z., Tang, G., Cai, J. (2014): Simultaneous determination of water soluble ions in $\mathrm{PM}_{10}$ by ion chromatography. - Chinese Journal of Analysis Laboratory 33(1): 3942.

[30] Zhao, P. S., Dong, F., Yang, Y. D. (2013): Characteristics of carbonaceous aerosol in the region of Beijing, Tianjin, and Hebe, China. - Atmosphere Environment 71: 389398.

[31] Zhi, G R, Chen, Y J, Xue, Z G., Meng, F., Cai, J., Sheng, G., Fu, J. (2014): Comparison of elemental and black carbon measurements during normal and heavy haze periods: implications for research. - Environmental Monitoring and Assessment 186(10): 6097-6106. 